\title{
The evolutionary history of Drosophila buzzatii. XXIV. Second chromosome inversions have different average effects on thorax length
}

\author{
ESTEBAN HASSON, JUAN J. FANARA, CONSTANTINA RODRIGUEZ, JUAN C. VILARDI*, \\ OSVALDO A. REIG \& ANTONIO FONTDEVILA $\dagger$ \\ GIBE Departamento de Ciencias Biológicas, Facultad de Ciencias Exactas y Naturales. Universidad de Buenos Aires, \\ Ciudad Universitaria Pab. II, 1428 Buenos Aires, Argentina, *Laboratorio de Genética, Departamento de Ciencias \\ Biológicas, Facultad Ciencias Exactas y Naturales, Universidad de Buenos Aires, Ciudad Universitaria, 1428 Buenos \\ Aires, Argentina and tDepartmento de Genética y Microbiologia, Universidad Autónoma de Barcelona, 08193 Bellaterra \\ (Barcelona), Spain
}

\begin{abstract}
We demonstrate a genetic correlation between rearrangements of the second chromosome of $D$. buzzatii and thorax length, as a measure of body size. The results indicate that $2 j$ and $2 j z^{3}$ arrangements are correlated with large size, whereas $2 s t$ arrangement is correlated with small size. Some inversions $\left(2 s t\right.$ and $\left.2 j z^{3}\right)$ show dominant effects and others $\left(2 j / j^{z} 3\right)$ exhibit overdominance. These results show that at least 25 per cent of body size variation may be accounted for by the studied karyotypes. The possible integration of the genotypic, phenotypic and fitness levels, and also the possible implications to life-history evolution theories, are discussed. These results suggest that, under moderate to high heritability values, some kinds of chromosomal endocyclic and/or balancing selection may be valuable mechanisms for maintenance of body size variation.
\end{abstract}

Keywords: body size, chromosomal inversions, Drosophila buzzatii, fitness, selection, life-history traits.

\section{Introduction}

Although the adaptive basis of chromosomal polymorphisms in Drosophila is universally accepted, the selective forces involved are only inferred from indirect evidence from natural and experimental populations (Sperlich \& Pfriem, 1986). Direct demonstrations of the selective significance of these inversion polymorphisms in nature are practically nonexistent (Endler, 1986). In recent years, however, it has been possible to show that selection acts directly on these polymorphisms through several fitness components in natural populations (Anderson et al., 1979; Ruiz et al., 1986; Salceda \& Anderson, 1988; Ruiz \& Santos, 1989; Santos et al., 1989; Hasson et al., 1991).

Bearing in mind that selection acts primarily at the phenotypic level and only secondarily at the genotypic one, population biologists have been searching for a fit-

Correspondence: A. Fontdevila, Department of Ecology and Evolutionary Biology, University of California, Irvine, California 92717, U.S.A. ness-related morphometric character that is easy to observe and measure. Body size is one such trait. Several studies have shown that thorax length, as a measure of body size is correlated with adult fitness components, e.g. fecundity (Robertson 1957a, b), mating success (Butlin et al., 1982; Taylor et al., 1987; Partridge et al., 1987; Santos et al., 1988; Taylor \& Kekić, 1988), and longevity (Partridge et al., 1987).

Nonetheless, the existence of a relationship between the phenotype and the chromosomal rearrangements is rather controversial. Lande (1979) and John (1983) claim that chromosomal repatternings have no effect on the morphological exophenotype. However, a positive relationship has been postulated in some insect species, although a significant correlation has only been demonstrated in a few cases (White \& Andrew, 1960; White et al., 1963; Butlin et al., 1982; Colombo, 1989). As regards species of Drosophila, a relationship between body size and chromosome polymorphism was also reported for the D. subobscura A chromosome (Krimbas, 1967) and for the D. pseudoobscura 
third chromosome (Thomson, 1971). Additional evidence pointing to the effect of chromosomal variation on morphological characters comes from the correlated response of chromosomal frequencies to phenotypic artificial selection in D. subobscura (Prevosti, 1960; Prevosti 1967) and D. pseudoobscura (Druger, 1962).

Data on the genetic basis of body size in natural populations is of high relevance to the understanding of the evolutionary consequences of natural phenotypic selection. In D. buzzatii, Santos et al., (1988) and Ruiz \& Santos (1989) have found that body size is positively correlated with mating success in a Spanish natural population. These studies have also shown that different karyotypes differ in their mean value for thorax length (Ruiz \& Santos, 1989). In this paper we present data showing that non-inbred flies with different second chromosome karyotypes extracted from an Argentinian natural population differ significantly in their thorax lengths and we give some information on the genetic determination of the chromosomal polymorphism on body size.

\section{Materials and methods}

\section{The species Drosophila buzzatii}

D. buzzatii is a cactophilic species of the repleta group (mulleri complex) that breeds mainly in the rotting cladodes of cacti belonging to several Opuntia species. It probably originated in Argentina (Fontdevila, 1981; Fontdevila et al., 1982) and has successfully colonized the Mediterranean region (Fontdevila et al., 1981; Fontdevila, 1981; 1989) and Australia (Barker, 1982) following its natural host plants. Chromosomally, this species is highly polymorphic mainly for its second chromosome (Ruiz et al., 1985), and fitness differences have been demonstrated among these arrangements (Ruiz et al., 1986; Hasson et al., 1991).

\section{Derivation of homokaryotypic stocks}

We analysed flies derived from a collection performed in May 1987 at Arroyo Escobar, a locality situated 30 $\mathrm{km}$ north-west of Buenos Aires city (for a description of the population, see Fontdevila et al., 1982). Previous studies showed that this population is polymorphic for four arrangements in the second chromosome $\left(s t, j, j z^{3}\right.$ and $j q^{7}$ ) and two in the fourth ( $s t$ and $s$ ) (Fontdevila $e t$ al., 1982).

Three homokaryotypic stocks involving 17, 14 and 4 independently derived chromosomes were obtained for the second chromosome arrangements: $2 j, 2 j z^{3}$ and
$2 s t$, -respectively. The karyotypes of each collected female and her mate were identified by analysing the polytene chromosomes of 11 progeny larvae. In a few cases both parents were homozygous for the $2 j$ arrangement and these isofemale lines were selected as homokaryotypes. However, most of the lines were segregating and the homokaryotypic lines had to be obtained by progeny selection of full sib crosses. This progeny testing was determined with an accuracy higher than 95 per cent by the cytological analysis of 13 progeny larvae (Barbadilla \& Naveira, 1988). The lines did not attain fixation simultaneously and some lines were kept by mass culturing until all the homokaryotypic lines were obtained. The maximum number of generations before fixation was five.

The experimental homokaryotypic stocks were founded with eggs collected in optimal conditions from egg-laying cages, similar to those described by Ruiz et al. (1986). For each homokaryotypic stock, a total of 150 mature (4-5 day-old) virgin males and 150 mature virgin females of the same homokaryotypic lines were introduced into one of these cages. Each homokaryotypic line contributed with equal numbers of flies to this founding population. A large sample of collected eggs was seeded in a culture and this stock was maintained by mass culturing during four generations before the experiment was initiated.

\section{Derivation and analysis of different karyotypes}

A total of nine (Table 1) homo- and heterogametic crosses were conducted by introducing 100 mature (4-5 day-old) virgin males and 100 mature females of the homokaryotypic stocks to egg collecting chambers. Reciprocal heterogametic crosses were performed in order to test possible maternal effects.

Eggs were allowed to hatch and first instar larvae were seeded in culture vials at optimal density, i.e. 40 larvae in $6 \mathrm{ml}$ of culture medium, as determined by Fanara (1988). Eight to ten replicates were run simultaneously for each cross. Cultures were maintained at $25^{\circ} \mathrm{C}$ under continuous light until all adult flies emerged. A random sample of each progeny was measured $24 \mathrm{~h}$ after individual emergences. Thorax length was measured to the nearest $0.025 \mathrm{~mm}$ with a binocular microscope fitted with an ocular micrometer. The measure was taken from the anterior margin of the thorax to the posterior tip of the scutellum, as laterally viewed. All measurements were done by one of us (JJF).

A modified formula of David's killed yeast culture medium (David, 1962) was employed. Polytene chromosome slides were obtained following the technique described by Fontdevila et al.(1981). 


\section{Statistical analysis}

ANOvA with sex and karyotype as fixed factors and replicates as a random factor nested in karyotypes was employed for the analysis of data. The mixed model employed can be expressed as:

$X_{i j k l}=\mu+\alpha_{i}+\beta_{j}+F_{k(j)}+(\alpha \beta)_{i j}+(\alpha F)_{i k}+\varepsilon_{i j k l}$

where $X_{i j k l}$ is the individual value; $\mu$ is the overall mean; $\alpha_{i}$ is the sex effect, fixed; $\beta_{j}$ is the karyotypic effect, fixed; $F_{k(j)}$ is the replicate factor nested in karyotypes, random; $(\alpha \beta)_{i j}$ is the sex by karyotypic interaction; $(\alpha F)_{i k}$ is the sex by replicate interaction; and $\varepsilon_{i j k l}$ is the random error.

This ANOVA analysis gives only a partial view of the karyotype effects on thorax length. We have extended our analysis by fitting our data to a diallel design (Mather \& Jinks, 1982) in which all possible crosses are performed among a set of fixed homokaryotypic lines. This diallel design can be tested by a two-way ANOva with paternal and maternal karyotypes as fixed factors, with each cell observation as the average thorax length for each replicate.

A posteriori comparisons were performed utilizing the method of Scheffe. This and all statistical methods employed can be found in Sokal \& Rohlf (1981). Computations were performed with SPSS and BMDP statistical packages.

\section{Results}

The mean thorax length of males and females bearing different second chromosome karyotypes is shown in Table 1. The ANova is shown in Table 2. There are highly significant differences among sexes and among karyotypes. The among-replicate (within karyotype) variation is also highly significant which suggests that despite the homogeneity of the experimental conditions, environmental variance could be relatively high. On the other hand, there is neither sex-karyotype interaction nor sex-replicate interaction, indicating that thorax length variation behaves independently of sex across genotypes or laboratory environments. The between-sex consistency of the mean thorax lengths (Table 1) was also analysed by using the Kendall rank correlation coefficient (Sokal \& Rohlf, 1981). The value of this statistic $(n=64)$ was highly significant indicating that the rank order of karyotypes, according to their thorax length, is not statistically different between sexes.

The relative importance of karyotype on thorax length determination was measured by estimating the percentage contribution of each source of variation to
Table 1 Mean thorax length and the corresponding standard error for the different second chromosome karyotypes of $D$. buzzatii. Sample sizes are indicated in parenthesis

\begin{tabular}{llll}
\hline $\begin{array}{l}\text { Karyotypes } \\
(*)\end{array}$ & $\begin{array}{l}\text { Number of } \\
\text { replicates }\end{array}$ & $\begin{array}{l}\text { Male thorax } \\
\text { length }(\mathrm{mm})\end{array}$ & $\begin{array}{l}\text { Female thorax } \\
\text { length }(\mathrm{mm})\end{array}$ \\
\hline$s t / s t$ & 10 & $\begin{array}{l}1.0273 \pm 0.0304 \\
(116)\end{array}$ & $\begin{array}{l}1.1288 \pm 0.0277 \\
(119)\end{array}$ \\
& & $1.0396 \pm 0.0287$ & $1.1303 \pm 0.0280$ \\
$j / j$ & 10 & $(135)$ & $(131)$ \\
& & $1.0530 \pm 0.0294$ & $1.1499 \pm 0.0262$ \\
$j z^{3} / j z^{3}$ & 10 & $(158)$ & $(161)$ \\
& & $1.0365 \pm 0.0276$ & $1.1347 \pm 0.0229$ \\
$s t / j$ & 8 & $118)$ & $(130)$ \\
& & $(152)$ & $1.0215 \pm 0.0288$ \\
$j / s t$ & 10 & $1.0242 \pm 0.0267$ & $1.1285 \pm 0.0253$ \\
& & $(160)$ & $(137)$ \\
$s t / j z^{3}$ & 10 & $1.0410 \pm 0.0282$ & $1.1473 \pm 0.0288$ \\
& & $(146)$ & $(146)$ \\
$j z^{3} / s t$ & 10 & $1.0647 \pm 0.0228$ & $1.1532 \pm 0.0225$ \\
& & $(151)$ & $(146)$ \\
$j / j z^{3}$ & 10 & $1.0710 \pm 0.0241$ & $1.1701 \pm 0.0279$ \\
& & $(136)$ & $(153)$ \\
$j z^{3} / j$ & 10 & &
\end{tabular}

$\left.{ }^{*}\right)$ The chromosome of male parental origin is indicated in the first term.

Table 2 Analysis of variance testing for differences in thorax length among second chromosome karyotypes of Drosophila buzzatii

\begin{tabular}{|c|c|c|c|c|c|}
\hline $\begin{array}{l}\text { Source of } \\
\text { variation }\end{array}$ & d.f. & SS & MS & $F$ & $P$ \\
\hline Sex & 1 & 6.24 & 6.24 & 2466.24 & 0.000 \\
\hline Karyotypes & 8 & 0.66 & 0.08 & 31.62 & 0.000 \\
\hline \multicolumn{6}{|l|}{ Sex by } \\
\hline karyotype & 8 & 0.02 & $2.50 \times 10^{-3}$ & 0.99 & 0.450 \\
\hline Replicates & 79 & 0.20 & $2.53 \times 10^{-3}$ & 3.89 & 0.000 \\
\hline \multicolumn{6}{|l|}{ Sex by } \\
\hline replicates & 79 & 0.07 & $8.90 \times 10^{-4}$ & 0.35 & 0.999 \\
\hline Error & 2366 & 1.53 & $6.50 \times 10^{-4}$ & & \\
\hline Total & 2541 & 8.72 & & & \\
\hline
\end{tabular}

the total variance. The results of ANOvA performed independently in each sex were strikingly consistent between sexes (data not shown), showing that about 25-29 per cent of size variance may be accounted for by the karyotypic factor. The among replicate component showed an acceptable value (9 per cent) for most experimental designs. The residual error, which represents a very important fraction of the total vari- 
Table 3 Two-way analysis of variance according to a diallel design testing for differences in thorax length among second chromosome inversions of $D$. buzzatii transmitted via male and female parents

\begin{tabular}{lrllll}
\hline $\begin{array}{l}\text { Source of } \\
\text { variation }\end{array}$ & d.f. & SS & MS & $F$ & $P$ \\
\hline $\begin{array}{l}\text { Males } \\
\quad \text { Parental }\end{array}$ & & & & & \\
$\quad \begin{array}{l}\text { males } \\
\quad \text { Parental }\end{array}$ & 2 & 0.01104 & 0.00552 & 39.08 & 0.000 \\
$\quad$ females & 2 & 0.00704 & 0.00352 & 24.90 & 0.000 \\
$\quad$ Interaction & 4 & 0.00751 & 0.00188 & 13.28 & 0.000 \\
$\quad$ Error & 79 & 0.01116 & 0.00014 & & \\
$\begin{array}{l}\text { Females } \\
\quad \text { Parental }\end{array}$ & & & & & \\
$\quad$ males & 2 & 0.01022 & 0.00511 & 32.27 & 0.000 \\
$\quad \begin{array}{l}\text { Parental } \\
\text { females }\end{array}$ & 2 & 0.00148 & 0.00074 & 4.67 & 0.012 \\
$\quad$ Interaction & 4 & 0.00645 & 0.00161 & 10.19 & 0.000 \\
$\quad$ Error & 79 & 0.01251 & 0.00016 & & \\
\hline & & & & & \\
\hline
\end{tabular}

ance (62-66 per cent), may be mainly explained as a consequence of the genetic background.

In order to obtain a further understanding of the effects of different arrangements, two types of analyses were performed: (a) diallel analysis, and (b) Scheffe's paired comparisons. Table 3 shows the two-way ANOvA using a diallel design. Differences among arrangements are highly significant in both parental sexes and there are no differential contributions between sexes to the total variance. The latter can be tested by using the $F$ statistics produced by the ratio of female-to-male parent variance components. None of these $F$ ratios is statistically significant (males: $F_{2,2}=1.57, P=0.33$; females: $F_{2,2}=6.91, P=0.13$ ). This suggests that maternal effects do not exist. A corroboration of this has been provided by paired comparisons among means of reciprocal crosses using Scheffe's method. Differences were only significant in one out of six possible comparisons and, consequently, maternal effects were considered negligible and thorax lengths of reciprocal heterokaryotypes were averaged for future comparisons.

The relative contribution of each rearrangement to body size variability can be assessed by multiple stepwise regression analysis (BMDP2R subprogram, in BMDP, 1988) of body size on increasing doses of each rearrangement. St rearrangement decreases size significantly ( $r$ male value: $-0.1070, P<0.01 ; r$ female value: $-0.0130, P<0.01)$ and makes a large contribution to size variation (32 per cent averaged among sexes). A smaller, although significant contribution (2.7 per cent) to male size variation (but not to female size variation) can be assigned to $2 j z^{3}$ in the direction of increasing body size. No significant contribution of $2 j$ to size variation has been detected.

Interaction between male and female parents is highly significant in both sexes (Table 3), which suggests deviations from additivity. In order to understand these non-additive effects, the thorax length of different karyotypes carrying 2, 1 or 0 chromosomes with each rearrangement were compared using the $a$ posteriori Scheffe's method. Rearrangements $2 S t$ and $2 j z^{3}$ exhibit dominant effects of opposite signs. Thus, homo- and heterokaryotypes for these rearrangements exhibit non-significantly different sizes $(S t / S t$ versus $S t)$ + : male $F_{8,79}=0.116$, female $F_{8,79}=0.359 ; j z^{3} / j z^{3}$ versus $j z^{3} /+$ : male $F_{8,79}=0.059$, female $F_{8,79}=0.027$ ), but both karyotypes are statistically different from nonbearing $(+/+)$ flies $(S t / S t$ : male $F=5.84$, female $F=4.35 ;$ St $/+$ : male $F=12.78$, female $F=6.36$; $j z^{3} / j z^{3}:$ male $F=3.46$, female $F=3.37 ; j z^{3} /+:$ male $F=5.98$, female $F=6.29$. All $F$ values significant at $P<0.01$ for 8 and 79 d.f.). Similar tests for overdominant effects show significant values only for the $j / j z^{3}$ heterokaryotype (male $F_{8,79}=7.26, \quad P<0.01$; female $F_{8,79}=4.45, P<0.01$ ).

\section{Discussion}

Latitudinal phenotypic variation in body size (Prevosti, 1955; Misra \& Reeve, 1964) has been interpreted as a genetic adaptation (Pfriem, 1983), but a pure phenotypic response to environmental variation cannot be excluded. In the $D$. buzzatii natural population of Carboneras (Spain), the significant correlation between body size and karyotype frequency (Ruiz \& Santos, 1989) may not have a genetic cause. The authors mention at least two non-genetic explanations. Firstly, body size and karyotype might be independently correlated with longevity. Secondly, if karyotype polymorphism is subjected to multiple niche selection, some karyotypes may select niches that favour a specific adult size. The results presented here may rule out both environmental explanations. Our experiment is performed with flies of the same age reared in similar conditions. The percentage of total-variance assigned to genetic (karyotypic) causes is high $\cdot(25-29$ per cent) in both sexes. A similar conclusion can be inferred from a recent laboratory study in the population of Carboneras (Spain) (Ruiz et al., 1991).

It can be argued that the low values of thorax length of $2 s t / s t$ karyotypes may be a consequence of the inbreeding depression produced by the low number of independently derived $2 s t$ chromosomes that originated the homokaryotypic stock. This seems unlikely. When 2st/st homokaryotypes are compared with 
$2 s t /+$ heterokaryotypes, non-significant size differences are obtained, a result that contradicts the putative inbreeding depression of $2 s t / s t$. Moreover, the estimated mean size of the $2 s t / s t$ karyotype (Table 1) shows no significant increase in its standard error, as expected if this line was highly inbred.

In all these studies with $D$. buzzatii there is a striking coincidence in the effects of second chromosome arrangements on body size. The lowest size always corresponds to the $2 s t / s t$ and the effect of arrangements of the $j$ phylad $(j, j z 3, j q 7)$ tends on average to increase in size. The karyotypic effects are similar in field studies (Ruiz \& Santos, 1989; Ruiz et al., 1991), although the among karyotype differences are statistically significant only in males and when the $2 j$ phylad arrangements are pooled. In these studies with wild flies, the phenotypic variance increases between 5 and 9 times that in laboratory studies, so the probability of detecting significant differences among karyotypes is diminished accordingly.

If the selective differences among chromosomal inversions of $D$. buzzatii were mediated by their effects on body size, one would be able to predict the expected correlations among karyotype, phenotype and fitness components. Ruiz \& Santos (1989) suggest that the effect of inversions on body size is responsible for the differences in male mating success. Applying this line of thinking one would expect that flies with similar body size (e.g. $2 j$ and $2 j z 3$ carriers) should share a common pattern of fitness components. This cannot be adequately tested for mating success because sample sizes are too small for some karyotypic classes in Ruiz \& Santos (1989) and the method of fitness component analysis used by Ruiz et al. , (1986) and Hasson et al., (1991) is not sensitive enough. Nonetheless, the analysis of fitness components by Hasson et al. (1991), on the same population studied here, seems to indicate that genetically small individuals $(2 s t)$ would be fitter at early stages and disadvantageous at later stages. In contrast, the same study by Hasson et al. (1991) shows that for the $2 j z^{3}$ arrangement, the antagonistic behaviour is verified between two late fitness components: longevity and fecundity, favouring the former and impairing the latter. It is clear from this that in complex chromosomal polymorphisms there is no simple relationship between body size karyotype and fitness components.

The evidence reported here and in previous works (Ruiz et al., 1986 Hasson et al., 1991) suggests that a type of endocyclic or balancing selection, although not a simple one, can be invoked to explain the maintenance of body size variation in nature. Nonetheless, the validity of this assertion has been challenged in view of the low heritability estimates for body size found by some authors in natural populations of Drosophila (Prout \& Barker, 1989, but see Coyne \& Beechan 1987). Low heritabilities due to high values of environmental variance result in nearly neutral genetic variance and no balancing selection is necessary to explain this variation. Thus, although the measure of heritability in nature is not easy, it is of utmost importance to disclose the mechanisms of maintenance of morphological variation. In this endeavour, the ecological structure of populations plays a leading role. Some ecological studies performed with $D$. buzzatii (Santos et al., 1989; Prout \& Barker, 1989) have shown that the ephemeral patchiness of rotting cladodes subdivides the populations in a way that positively enhances not only the local within-rot heritability estimates, but also the contribution of drift to genetic variation.

\section{Acknowledgements}

The authors wish to thank Lic. Rosa Liascovich for critical reading of the manuscript, Lic. Beatriz Gonzalez for her advise on the statisitical processing of data, and Drs Mauro Santos, Alfredo Ruiz and Michael Rose for helpful discussions and constructive criticisms of earlier versions of this manuscript. Dr Francesc Peris and $\mathrm{Mr}$ Antonio Barbadilla are thanked for critical reading of the manuscript and constructive discussions on the statistical treatment of the data. The authors are also indebted to Dr F. Peris for his help in the data processing with the BMDP package. This work is the result of a co-operative project between Argentina and Spain. It was supported in Argentina by a CONICET grant PIA 004-0422/87 and by Universidad de Buenos Aires grant EX038/87 awarded to O. A. Reig and in Spain by a DGICYT grant PB 850071 awarded to A. Fontdevila.

\section{References}

ANDERSON, W. W, LEVINE, L, OLVERA, O, POWELL. J. R, DE LA ROSA, M. E, SALCEDA, V. M, GASO, M. I. AND GUZMAN, J. 1979. Evidence for selection by male mating success in natural populations of Drosophila pseudoobscura. Proc. Natl. Acad. Sci., USA 76, 1519-1523.

BARBADILlA, A. AND NAVEIRA, J. 1988. The estimation of parental genotypes by the analysis of a fixed number of their offspring. Genetics 119, 465-472.

BARKER, J. S. F. 1982. Population genetics of Opuntia breeding Drosophila in Australia. In: Barker, J. S. F. and Starmer, W. T. (eds). Ecological Genetics and Evolution. Academic Press, Australia, pp. 209-224.

BMDP. 1988. Statistical Software. University of California Press, Berkeley, CA.

BUTLIN, R. K, READ, I. L. AND DAY, T. H. 1982. The effects of a 
chromosomal inversion on adult size and male mating success in the seaweed fly, Coelopa frigida. Heredity 49, $51-62$.

CоLомво, P. 1989. Chromosome polymorphisms affecting recombination and exophenotypic traits in Leptysma argentina (Orthoptera): A populational survey. Heredity 62, 289-299.

COYNE, J. A. AND BEECHAM, E. 1987. Heritability of two morphological characters within and among natural populations of Drosophila melanogaster. Genetics 117, 727-737.

DAVID, J. 1962. A new medium for rearing Drosophila in axenic conditions. Dros. Inf. Serv. 36, 128.

DRUGER, M. 1962. Selection and body size in Drosophila pseudoobscura at different temperatures. Genetics 47, 209-222.

ENDLeR, J. A. 1986. Natural Selection in the Wild. Princeton University Press, Princeton, N J.

faNARA, J. J. 1988. Parámetros de vida en Drosophila buzzatii. Seminario de Licenciatura. Facultad de Ciencias Exactas y Naturales, Universidad de Buenos Aires.

FONTDEVILA, A. 1981. ¿Cuánto polimorfismo cromosómico se pierde en la colonización? In: Reig, O. A. (ed.), Ecology and Genetics of Animal Speciation. Equinoccio, Caracas, Venezuela, pp. 69-99.

FONTDEVILA, A. 1989. Founder effects in colonising populations: The case of Drosophila buzzatii. In: Evolutionary Biology of Transient Unstable Populations. SpringerVerlag, Berlin, pp. 74-95.

FONTDEVILA, A., RUIZ, A., ALONSO, G. AND OCANA, J. 1982. The evolutionary history of Drosophila buzzatii. II How much has chromosomal polymorphism changed in colonization? Evolution 36, 843-851.

FONTDEVILA, A., RUIZ, A., OCANA, J. AND ALONSO, G. 1981. The evolutionary history of Drosophila buzzatii. I. Natural chromosomal polymorphism in colonized populations of the Old World. Evolution, 35, 148-157.

HASSON, E., VILARDI, J. C., NAVEIRA, H., FANARA, J. J., RODRIGUEZ, C., REIG, O. A. AND FONTDEVILA, A. 1991. The evolutionary history of Drosophila buzzatii. XX. Fitness component analysis in a natural endemic population from Argentina. J. Evol. Biol. 4, 209-225.

JOHN, B. 1983. The role of chromosome change in the evolution of orthopteroid insects. In: Sharma, A. K. and Sharma, A. M. (eds), Chromosomes in the Evolution of Eukaryotic Groups, Vol. 1, CRC Press, FL, pp. 1-114.

KRIMBAS, C. 1967. The genetics of Drosophila subobscura populations. III. Inversion polymorphism and climatic factors. Mol. Gen. Genet. 99, 133-150.

LANDE, R. 1979. Effective deme sizes during long-term evolution estimated from chromosomal rearrangements. Evolution 33, 324-251.

MATHER, K. AND JINKS, J. L. 1982. Biometrical Genetics. Chapman and Hall, London.

MISRA, R. K. AND REEVE, E. C. R. 1964. Clines in body size dimension in populations of Drosophila subobscura. Genet. Res. 5, 240-256.

PARTRIDGE, L., HOFFMAN, A. AND JONES, J. s. 1987. Male size and mating success in Drosophila melanogaster and Drosophila pseudoobscura under field conditions. Anim. Behav. 35, 468-476.

PFRIEM, P. 1983. Latitudinal variation in wing size in Drosophila subobscura and its dependence on polygenes in chromosome O. Genetica 61, 221-232.

PREVOSTI, A. 1955. Geographical variability in quantitative traits in populations of Drosophila subobscura. Cold. Spr. Harb. Symp. Quant. Biol. XX, 294-299.

PREvosT1, A. 1960. Cambios en la heterocigosis por inversión cromosómica al variar por selección la longitud del ala en Drosphila subobscura. Genet. Iber. 12, 27-41.

PREVOST1, A. 1967. Inversion heterozygosity and selection for winglength in Drosophila subobscura. Genet. Res. 10, 81-93.

PROUT, T. AND BARKER, J. S. F. 1989. Ecological aspects of the heritability of body size in Drosophila buzzatii. Genetics 123, 803-813.

ROBERTSON, F. W. 1957a. Studies in quantitative inheritance. X. Genetic variation of ovary size in Drosophila. J. Genet. 55, 410-427.

ROBERTSON, F. W. 1957b. Studies in quantitative inheritance. XI. Genetic and environmental correlation between body size and egg production in Drosophila melanogaster. $J$. Genet. 55, 428-443.

RUIZ, A., FONTDEVILA, A., SANTOS, M., SEOANE, M. AND TORROJA, E. 1986. The evolutionary history of Drosophila buzzatii. VIII. Evidence for endocyclic selection acting on the inversion polymorphism in a natural population. Evolution 40, 740-755.

RUIZ, A., NAVEIRA, H. AND FONTDEvila, A. 1985. La historia evolutiva de Drosophila buzzatii. IV. Aspectos citogenéticos de su polimorfismo cromosómico. Genét. Ibér. 36, 13-35.

RUIZ, A. AND SANTOS, M. 1989. Mating probability, body size and inversion polymorphism in a colonizing population of Drosophila buzzatii. In: Fontdevila, A. (ed.), Evolutionary Biology of Transient Unstable Populations. SpringerVerlag, Berlin, pp. 96-113.

RUIZ, A., SANTOS, M., BARBADILLA, A., QUEZADA-DIAZ, J. E., HASSON, E. AND FONTDEVILA, A. 1991. The evolutionary history of Drosophila buzzatii. XVIII. Genetic variance for body size in a natural population of Drosophila buzzatii. Genetics, 128, 739-750.

SALCEDA, v. M. AND ANDERSON, w. w. 1988. Rare male mating advantage in a natural population of Drosophila pseudoobscura. Proc. Natl. Acad. Sci., U.S.A. 85, 9870-9874.

SANTOS, M., RUIZ, A., BARBADILLA, A., QUEZADA-DIAZ, J. E., HASSON, E. AND FONTDEVILA, A. 1988. The evolutionary history of Drosophila buzzatii. XIV. Larger flies mate more often in nature. Heredity 61, 255-262.

SANTOS, M., RUIZ, A. AND FONTDEVILA, A. 1989. The evolutionary history of Drosophila buzzatii. XIII. Random differentiation as a partial explanation of chromosomal variation in a structured natural population. Am. Natur. 133, 183-197.

SOKAL, R. R. AND ROHLF, F. J. 1981. Biometry. 2nd ed. W. H. Freeman, New York.

SPERLICH, D. AND PFRIEM, P. 1986. Chromosomal polymorphisms in natural and experimental populations. In: 
Carson, H. L., Ashburner, M. and Thompson, J. N. (eds.), Genetics and Biology of Drosophila. Vol. 3e, Academic Press, London, pp. 257-309.

TAYLOR, C. E. AND KEKIC, B. 1988. Sexual selection in a natural population of Drosophila melanogaster. Evolution 42, 197-199.

TAYLOR, C. E., PEREDA, A. D. AND FERRARI, J. A. 1987. On the correlation between mating success and offspring quality in Drosophila melanogaster. Am. Natur. 129, 721-729.

THOMSON, J. A. 1971. Association of karyotype, body weight and resistance of dissecation in Drosophila pseudoobscura. Can. J. Genet. Cytol. 13, 63-69.

WHITE, M. J. D. AND ANDREW, L. E. 1960. Cytogenetics of the grasshopper Moraba scurra. V. Biometric effects of chromosomal inversions. Evolution 14, 284-292.

WHITE, M. J. D., LeWONTIN, R. C. AND ANDREW, L. E. 1963. Cytogenetics of the grasshopper Moraba scurra. VII. Geographic variation of adaptive properties of inversions. Evolution 17, 147-162. 